\title{
Pertussis Vaccine; the Past, the Present and the Future (A Mini Review)
}

\author{
Article by Frank Adusei-Mensah \\ Ph.D., Public Health, Texila America University \\ E-mail:drfrank83@gmail.com
}

\begin{abstract}
The inception of the whole cell pertussis vaccine wP saw global reduction in reported cases, mortality and morbidity burden to the disease. But, in the late 90s, wP was replaced with acellular pertussis vaccine $(a P)$ in most countries due to safety reasons. In recent years however, the annual reported cases of pertussis globally have increase greatly even among highly vaccinated groups, ${ }^{1} ;{ }^{2}$. This nurtures concerns about the level of protection aP bestows on the vaccinated individuals, ${ }^{2}$. The aim of this current mini review is therefore to assess some recent reports and developments on the matter, evaluate how alarming the situation is by comparing the present to the past and the recommendations for roadmap into the future.

Methodology: Boolean search was carried out on popular sites like PubMed and Google on publications and reviews on the topic.

Results: Some researchers have attributed the recent surge in reported pertussis cases and deaths to reasons like waning of vaccine induced immunity, inefficacy, resistant strain development and mutated forms in the pathogenic bacteria.

Conclusion: For a successful control and eradication of the pertussis disease, new strategies needed to be implemented to factor in the estimated waning effect; $27 \%$ / year of 4 years in total reduction in efficacy. Multicomponent aP vaccine $(n>3)$ has also been reported to be as effective as the wP vaccine hence modification of the current aP vaccine or re-visiting of $w P$ is can also be considered.
\end{abstract}

\section{Introduction}

Pertussis disease, also known as whooping cough, is a droplets contagious respiratory disease caused by Bordetella pertussis bacterium, ${ }^{3} ;{ }^{4}$. It affects all ages mostly children, ${ }^{5} ;{ }^{6}$ and has burdened humanity and public health care systems for centuries. French scientist; Guillaume de Baillou pioneered research into pertussis disease in 1578 which attracted the interest of many scientists leading to the development and licensing of pertussis vaccines in 1914 in the United States of America (USA), ${ }^{6}$. The bacteria attaches to the cilia of the upper respiratory tract and produces toxins which damages the cilia, inflames the airways and paralyzes parts of the respiratory cells, ${ }^{7} ;{ }^{8}$. Whooping sound may follow bouts of rapid coughing, the toxins produce inflammation in the respiratory tract with mild to severe cough, ${ }^{9} ;{ }^{10}$. The most virulent form of the bacteria strain in infants is the B. pertussis pneumonia. According previous studies, the bacteria has complex array of adhesins, aggressins and toxins that are important for colonization, survival and propagation in the human host, ${ }^{8} ;{ }^{11}$. Some scientists believe that the organism has the ability to undergo reversible mutations in response to the environment or treatment as part of its sophisticated mechanism, ${ }^{8}$ and this has been associated to the recent upsurge of the disease and a possible development of mutated and resistant strains ${ }^{3.4}$

The disease is found in humans and all human race have the chance of catching the disease, ${ }^{7}$. The group specific prevalent rates for the (0-1) years age-group and (10-14) years age-group are high, ${ }^{5} ;{ }^{6}$. Mortality among children under six years old is the highest ${ }^{5}$. Vaccination and health promotion programmes are believed to be the most effective public health arsenal to preventing and controlling the disease, ${ }^{12}$. Immunization against pertussis is the best window in preventing the disease and an effective and reliable vaccine is the ultimate of researchers and health practitioners. Many countries switched to acellular aP vaccine due to its reduced vaccine related interactions compared to $\mathrm{wP}$ vaccine. The disease 
DOI: $10.21522 /$ TIJPH.2013.06.02.Art016

ISSN: $2520-3134$

is once again becoming a public health concern due to increased number of cases in recent years and the resurgence of the disease in many countries. The recent developments raises eyebrows about the efficacy of the current aP vaccine regime, ${ }^{13} ;{ }^{14} ;{ }^{15}$. The aim of this study therefore is to assess some recent reports and developments on the matter, evaluate how alarming the situation is by comparing the present to the past and the recommendations for roadmap into the future.

Conventional vaccines are developed with either killed or inactivated whole pathogenic cell, extract or part of the pathogenic organism to induce immune response in the host system (fig. 1), ${ }^{16}$. It could also be done through the reverse vaccinology path using in-silico computer aided vaccine design approach, 16. Pertactin (Prn) protein, fimbriae 2 (Fim2) and fimbriae 3 (Fim3) of B. pertussis are virulence factors and immunogens used in some aP vaccines whiles the inactivated whole cells are used in wP vaccine, ${ }^{17}$; 18 .

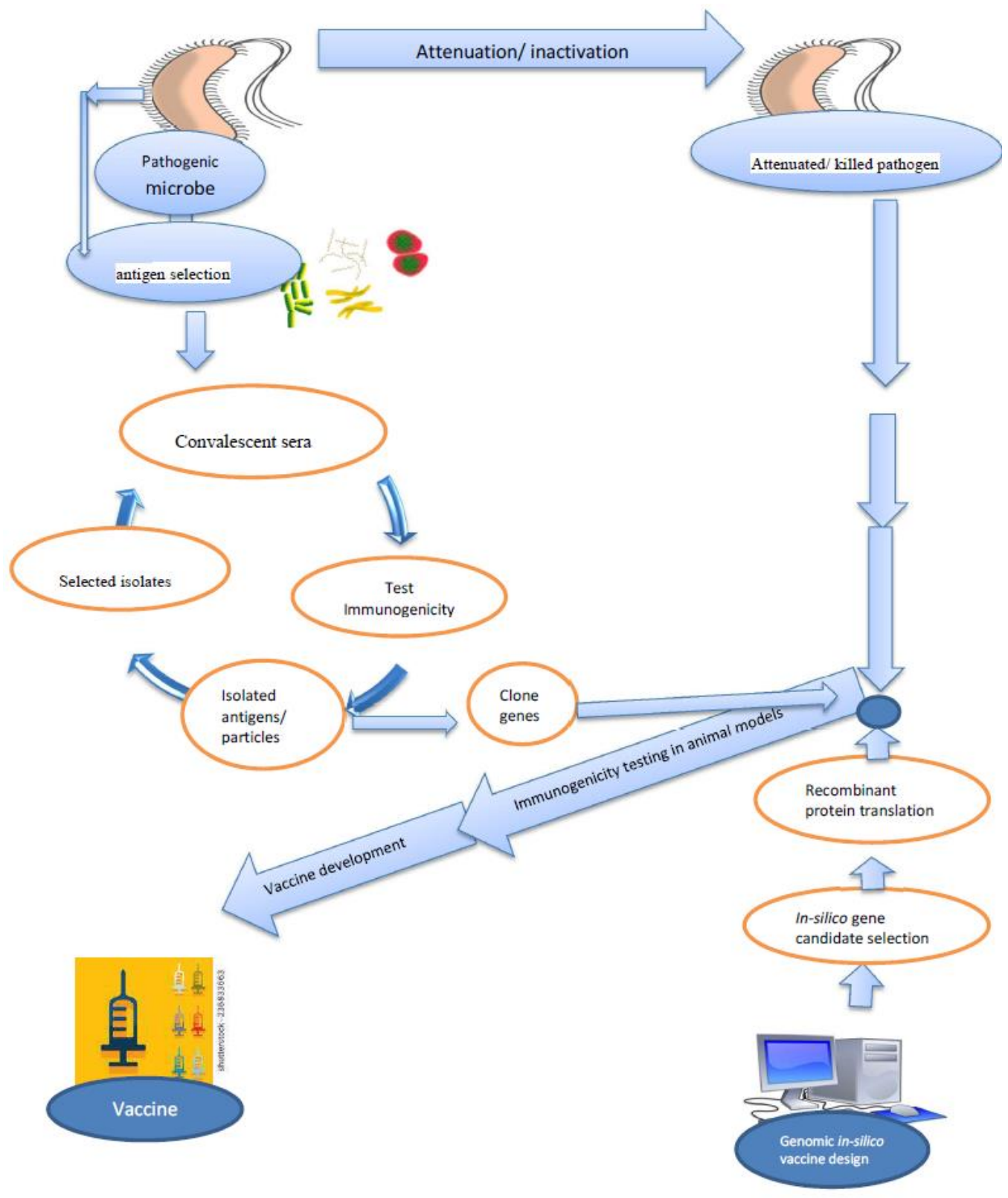

Figure 1. Schematic vaccine representation of conventional vaccine development 


\section{Pertussis disease and ap pertussis vaccine, the past}

Discovered by the American pediatrician Leila Daughtry-Denmark in late 1930s, the whole cell pertussis vaccine was introduced into the mainstream healthcare system in the late $1940 \mathrm{~s},{ }^{19} ;{ }^{20}$. The introduction of the whole cell pertussis vaccine (wP) into the mainstream healthcare system led to over $52 \%$ reduction in incidence of the disease from 156,517 in 1947 to just 74,715 in 1948 (fig. 2) in US alone. Other parts of the globe also experience the efficacies of the wP vaccine marked by reduced infection rates; ${ }^{21}$. In 1976, only 1,010 cases of incidence were reported in the United States ${ }^{22}$. Its introduction led to a drastic drop in the outbreak and mortality of the disease by over $90 \%$ globally, (WHO, 2015). In the US alone, there was a drastic drop in the annual reported cases from 120,718 in 1950 to 2,719 in 1991 (fig. 2) prior to the introduction of the acellular pertussis vaccine (DTaP), ${ }^{23}$. The wP gave immune protection to the individuals well into their teen ages, ${ }^{24}$. The success story of the whole cell vaccine was marred with the reports of severe adverse drug reactions. In the 1990s, the whole cell pertussis vaccine was replaced with acellular antigenic version due to reasons of safety and adverse drug reactions including febrile seizures, high fevers, fainting and unconfirmed reports of brain damage, comas, paralysis and death ${ }^{25}$; CDC 2015).

\section{aP pertussis vaccine; the present}

The pertussis disease is re-emerging in recent years with increasing number of reported annual outbreaks globally despite the high coverage of pertussis vaccination in recent years in many countries ${ }^{14}$; ${ }^{26} ;{ }^{27}$. There was an increase in reported cases and death in England and Wales for the year 2012 in almost a decade after aP vaccine replaced wP vaccine, ${ }^{28}$. An estimated 30.6 - 45 million pertussis cases and 390,000 deaths from pertussis in children younger than 5 years globally was reported for the year 1999, ${ }^{29}$; ${ }^{30}$. In 2015, there were more than 500 cases of pertussis in Maryland County in southern Liberia; the highest in decades ${ }^{31}$. In the United States, the number of annual reported cases begun to increase when the whole cell vaccine was replaced with the acellular version of the vaccine; from 2,719 in 1991 (fig. 2) to 25,827 in year 2004 and to 48,277 in $2012,{ }^{32}$. Vaccination coverage against pertussis infection globally is on the high side especially among developed countries, ${ }^{12} ;{ }^{28}$. Despite the high coverage, the outcome is not to the satisfaction of recipients and providers. The question is; what could be the cause? Some states and countries have modified their immunization strategy as a step towards solving the puzzle. In the US and UK, adults are vaccinated with pertussis vaccine with recommended boosters for pregnant women, ${ }^{33}$. In 2015, New Zealand modified its pertussis control strategy in hope of reducing the resurgence of the

disease, ${ }^{34}$. Chili among other states modified their pertussis control programs in view of the recent resurgence, ${ }^{35}$. Could it also be due to aP vaccine component and efficacy variations among aP vaccines; it was reported in a recent systematic revealed that multicomponent acellular pertussis $(\mathrm{aP})$ vaccine $(\mathrm{n}>$ 3) has protection efficacy of $84 \%$ to $85 \%$ against typical whooping cough, and from $71 \%$ to $78 \%$ in prevention for mild pertussis disease, ${ }^{24}$. The 1-component and 2-compoonent aP vaccines on the other hand gave much lesser protection against pertussis, with $22-41 \%$ odds of getting typical whooping cough and $42 \%-59 \%$ odds of getting mild pertussis disease ${ }^{24}$. Five component aP vaccine has also been reported to have similar effectiveness to wP vaccine whiles 3-component was less effective compared to wP vaccine, ${ }^{36}$.

\section{Waning of immune induced effect of aP vaccine}

It has been revealed that aP gives high immune response within the first few years after vaccination, but it decreases sharply after the fourth year of the last vaccination, ${ }^{37} ;{ }^{38} ;{ }^{39}$. Nicola reported that, after 5consecutive doses of a 3-component aP vaccine, the vaccine induced immunity wans $27 \%$ per year on average, ${ }^{40}$. Long-term follow-up study on vaccinated kids in Sweden by Gustafsson and colleagues revealed a similar pattern of waning and recommended booster dose be administered to children between 4-6 years after last vaccination, ${ }^{41}$. In 2011, Torres and colleagues reported that $86.4 \%$ of the incidence cases in the adolescent group were well vaccinated (Torres et al., 2011). In the US, there is more than six 
DOI: $10.21522 / \mathrm{TIJPH} .2013 .06 .02 . A r t 016$

ISSN: $2520-3134$

fold increase from 7867 in year 2000 to 48,277 in 2012, ${ }^{32}$ and according to Eshofonie and colleagues, all the cases of 2012 outbreak in a Rural Texas were fully vaccinated with $\mathrm{aP}^{13}$. The alarming rate of reemergence of the disease especially among the vaccinated group raises concerns about the longevity and waning effect of the acellular vaccine, ${ }^{42} ;{ }^{1}$. Reduced vaccine effectiveness, waning of vaccine induced protection and new strains/ mutations in the bacterial organism itself cannot be ignored when considering the reemergence of the disease, (fig. 3), ${ }^{43}$.

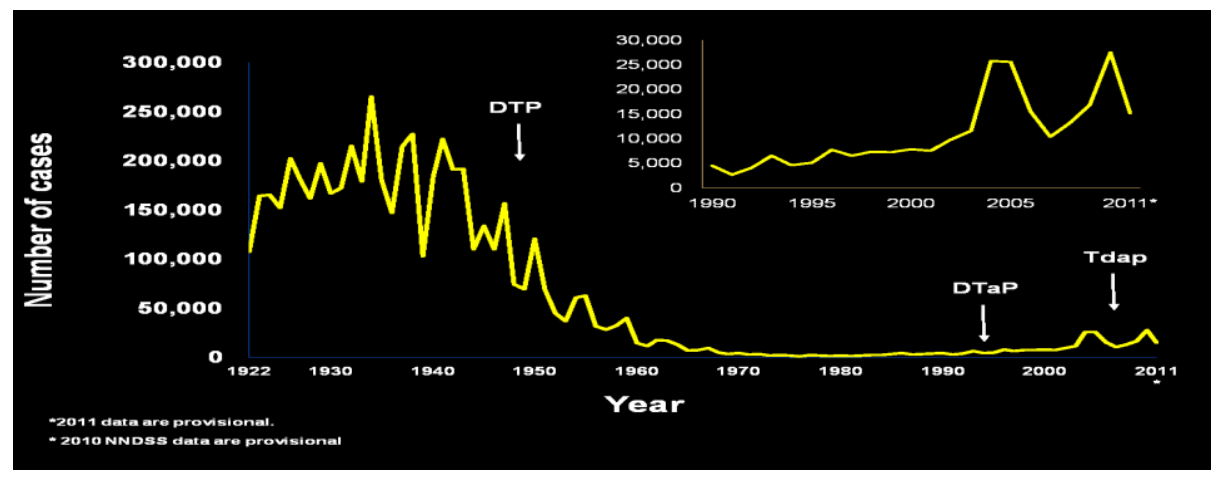

Figure 2. Reported pertussis cases: 1922-2011, USA

Source: CDC, National Notifiable Diseases Surveillance System and Supplemental Pertussis Surveillance System and 1922-1949, passive reports to the Public Health Service. The above chart from CDC shows that the pertussis disease spiked in 2011 despite the great reduction in incidence in the 70 s through to the early 90 s prior to the dawn of the DTaP vaccine.

\section{Reported cases of pertussis}

It is estimated that, 24.1 million cases of pertussis and about 160,700 deaths occur in children under 5 years of age per year globally, ${ }^{29}$. In the US alone, Pertussis has been a major concern since documentation begun in 1922 with tens of thousands of annual incidence recorded every year. According to CDC's report in 2012, annual incidence of 107,473 was recorded in year 1922, Over 264000 cases were reported in 1934 (fig. 2) and 183,866 cases in 1940, ${ }^{32}$. The CDC's 2012 report shows that pertussis disease is once again becoming a public health problem with $92 \%$ increase in incidence from the late 1990s to 2011 and beyond ${ }^{32} ;{ }^{13}$ In recent Valencia outbreak in Spain, about $90 \%$ of the pertussis cases had been vaccinated with DTaP vaccine ${ }^{39}$. There was a similar resurgence in New Zealand from 2011 to 2014 despite the over $90 \%$ success in DTaP vaccination rate ${ }^{44}$. In 2012, according to CDC's report, reported cases had risen by 17.8 folds from 2,719 in 1991 to 48277 in 2012 in US alone, of which 59\% of the 2012 cases had been well vaccinated (CDC, 2012), ${ }^{45}$. We are now witnessing the return of the pertussis epidemic. Surveillance reports from many countries reveals similar pattern about the reemergence of the disease which raises more questions about a possible waning immunity after vaccination with aP and or development of aP resistant strains of the Bordetella pertussis bacteria. Another question is why 9-11year age group in the vaccinated population is prone to the pertussis disease? Other concerns are about the fate of the populace vaccinated and whether it is economical at all to be given multiple shots of aP vaccine.

\section{Possible development of non-susceptible strains}

Possible development of vaccine resistant Bordetella pertussis bacteria strain(s) in the fight against pertussis epidermis should not be over-ruled. Research has shown that microbes can reduce permeability or uptake of a drug or vaccine and enhance efflux of the drug/vaccine from their system, ${ }^{46} ;{ }^{47} ;{ }^{4}$. They can also inactivate or stop producing filaments, enzymes or proteins which serve as target for the drug or vaccine; vaccines that target such proteins and hitherto were effective will no longer be effective against the organism, ${ }^{48} ;{ }^{46}$. The forth mechanism of microbial resistance to antibiotic and vaccines is by 
alteration or over-expression of the drug target ${ }^{48} ;{ }^{46}$. The microbes in this case might increase the quantity of the target protein, enzymes etc so that competitive inhibition will no longer be effective, ${ }^{46}$. Loss of enzymes involved in drug activation, ${ }^{46}$.

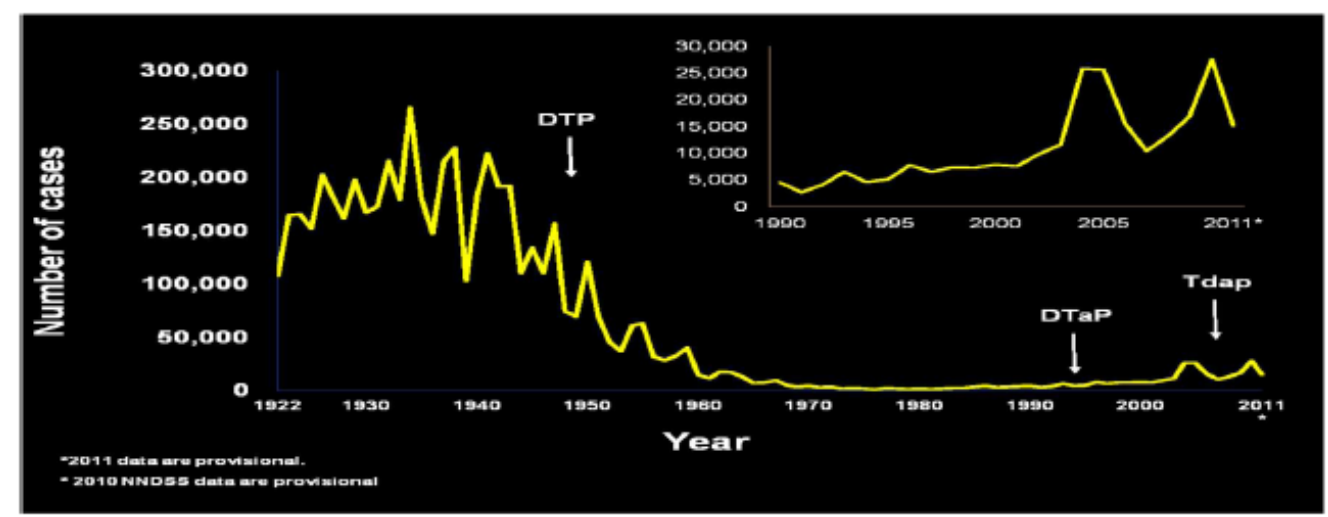

Figure 3. Schematic presentation of aP vaccine. The scheme presents a pictorial view of where we are and where we want to go in the fight towards pertussis disease

\section{DTaP pertussis vaccine, the future}

The whole cell vaccine with a pre-market trial efficacy of $78 \%$ proved to be effective during the 50 years of its reign against the disease (1940s- 1990s) fig 2; whiles the acellular version with $71 \%-85 \%$ efficacy rate from numerous premarket and post market trials kept losing the fight every year since its inception 25 years ago. Different post market field trials have been conducted around the globe but none did prove aP to be much inferior to wP, ${ }^{49} ;{ }^{50}$. Some researchers found the aP to be doing well than wP; $\left({ }^{18}, 51,{ }^{52} ;{ }^{53}\right.$. Zhang reported in a systematic review carried in 2011 that multi-component aP vaccine is as effective as wP, but the multi-component aP is more effective than less effective wP vaccine, ${ }^{54}$. In Senegal infants' trials in 1996, Simondon found aP to be safer with higher geometric mean titers for aP to $w P,{ }^{55}$. In some field trials, the pertussis toxoid containing filamentous haemagglutinin and pertactin (Bordetella outer membrane protein) were found to be comparable or even superior in efficacy to the whole cell pertussis vaccine (wP), ${ }^{56} ;{ }^{52}$. Is it because the efficacies of accellular aP vaccine is short-live and that the efficacies wans with time compared to the whole cell wP vaccine whose efficacies goes far into the teen age years, ${ }^{38}$ ? It is about time attention is giving in finding out the true cause of the recent surge in the incident rate of the pertussis disease. Could it be waning or vaccine resistance strain development? Researchers have found $B$. pertussis microbe to be a dynamic organism that continues to evolve with emerging new strains ${ }^{11} ;{ }^{57} ;{ }^{8}$. Recent studies by Jongerius et al found $B$. pertussis to have developed mechanism that enables it to suppress the full function of the current vaccines by developing complement evasion proteins such as autotransporter Vag8 ${ }^{58}$. Bordetella pertussis strains resistant to macrolide antibiotic treatment have also been reported ${ }^{37}$. The latest findings indicate that the causal organism is evolving and becoming resistant to the current regime calling for a modification of the current regime or an alternative vaccine. In the future, it is believed that if measures are not taken, pertussis disease will once again take its place among the re-emerged infectious diseases. Public health institutions and health care providers, researchers and the like should give sufficient attention to the disease and the $\mathrm{aP}$ in order to provide long term prevention for the disease and if possible eradicate it. As a result of the reemergence of pertussis disease among highly vaccinated children and adolescents, concerns are being raised about the durability of protection afforded by acellular vaccines, waning of the vaccine and a possible development of resistant Bordetella pertussis bacteria strain.

Future research and prevention strategies can reconsider modifying the current aP vaccine with new antigens; preferably multicomponent aP vaccine with reduced adverse vaccine interaction and improved effectiveness, ${ }^{24}$, using a live-attenuated vaccine ${ }^{59}$, altering the current aP vaccination schedule due to 
DOI: $10.21522 / \mathrm{TIJPH} .2013 .06 .02 . A r t 016$

ISSN: $2520-3134$

waning, ${ }^{60}$, developing a completely new vaccine or returning to the wP vaccine, ${ }^{60}$ could be the way into a brighter pertussis-free future (fig.1, 3).

\section{Conclusion}

The surveillance reports globally reveal that the pertussis disease is taken its place once again in the reemerging infectious diseases. The cause for the slip in protection is still an issue to be considered. It is a known fact that immunity acquired naturally wanes substantially in 7-20 years, ${ }^{38}$ and waning pertussis vaccine few years after vaccination is possible. The surveillance data on the outbreak reveals that the severity of the disease is reduced in the vaccinated group compared to the unvaccinated group. This indicates that the vaccination might have helped to reduce the severity and to a certain extent the number of incidence ${ }^{38}$, but the rate of re-emerging is still a major health concern ${ }^{42}$.

In considering the developments of the latter days based on the available scientific data, it has become imperative for providers and researchers to reconsider modifying the current aP vaccine with new antigens and/or adjuvants or from 1-3 component types into multicomponent, ${ }^{24}$, using a live-attenuated vaccine ${ }^{59}$, altering the current aP vaccination schedule, ${ }^{60}$, developing a completely new vaccine or returning to the $\mathrm{wP}$ vaccine, ${ }^{60}$

\section{Recommendations}

We recommend that pharmaceutical industries and funding agencies can shift their attention into funding field or clinical researches on pertussis vaccine resistant development and to come out with a measure that will once and for all help to eradicate pertussis disease. We also recommend the whole cell vaccine could be revisited by finding ways to reduce the adverse drug reactions to provide better protection with minimal risk or modifying the current regime.

\section{References}

[1]. Aslanabadi A, Ghabili K, Shad K, Khalili M, Sajadi MM. Emergence of whooping cough: notes from three early epidemics in Persia. Lancet Infect Dis. 2015; 15 (12):1480-1484. doi: 10.1016/S1473-3099(15)00292-3Torres J, Godoy P, Artigues A, et al. [Outbreak of whooping cough with a high attack rate in well-vaccinated children and adolescents]. Enferm Infecc Microbiol Clin. 2011; 29 (8):564-567. doi:10.1016/j.eimc.2011.04.005.

[2]. Bettinger JA, Halperin SA, De Serres G, Scheifele DW, Tam T. The effect of changing from whole-cell to acellular pertussis vaccine on the epidemiology of hospitalized children with pertussis in Canada. Pediatr Infect Dis J. 2007; 26 (1):31-35. doi:10.1097/01.inf.0000247055.81541.04.

[3]. Boughton CR. Pertussis vaccines: acellular versus whole-cell. Med J Aust. 1996; 164 (9):564-566.

[4]. Bolotin S, Harvill ET, Crowcroft NS. What to do about pertussis vaccines? Linking what we know about pertussis vaccine effectiveness, immunology and disease transmission to create a better vaccine. Pathog Dis. 2015;73 (8). doi:10.1093/femspd/ftv057.

[5]. Choi YH, Campbell H, Amirthalingam G, van Hoek AJ, Miller E. Investigating the pertussis resurgence in England and Wales, and options for future control. BMC Med. 2016; 14(1):121. doi: 10.1186/s12916-016-0665-8.

[6]. Crowcroft NS, Stein C, Duclos P, Birmingham M. How best to estimate the global burden of pertussis? Lancet Infect Dis. 2003; 3(7):413-418.

[7]. Clark TA. Changing Pertussis Epidemiology: Everything Old is New Again. J Infect Dis. 2014; 209(7):978981. doi:10.1093/infdis/jiu001.

[8]. Eshofonie AO, Lin H, Valcin RP, Martin LR, Grunenwald PE. An outbreak of pertussis in rural Texas: an example of the resurgence of the disease in the United States. J Community Health. 2015; 40(1):88-91. doi: 10.1007/s10900-014-9902-2.

[9]. Fedele G, Bianco M, Debrie A-S, Locht C, Ausiello CM. Attenuated Bordetella pertussis vaccine candidate BPZE1 promotes human dendritic cell CCL21-induced migration and drives a Th1/Th17 response. J Immunol Baltim Md 1950. 2011; 186(9):5388-5396. doi:10.4049/jimmunol.1003765. 
[10]. Forsyth K, Nagai M, Lepetic A, Trindade E. Pertussis immunization in the global pertussis initiative international region: recommended strategies and implementation considerations. Pediatr Infect Dis J. 2005; 24 (5 Suppl):S93-97.

[11]. Gent M van, Bart MJ, Heide HGJ van der, Heuvelman KJ, Mooi FR. Small Mutations in Bordetella pertussis Are Associated with Selective Sweeps. PLOS ONE. 2012; 7(9):e46407. doi:10.1371/journal.pone.0046407.

[12]. Guo B, Page A, Wang H, Taylor R, McIntyre P. Systematic review of reporting rates of adverse events following immunization: an international comparison of post-marketing surveillance programs with reference to China. Vaccine. 2013;31(4):603-617. doi:10.1016/j.vaccine.2012.11.051.

[13]. Gabutti G, Rota MC. Pertussis: A Review of Disease Epidemiology Worldwide and in Italy. Int J Environ Res Public Health. 2012; 9(12):4626-4638. doi:10.3390/ijerph9124626.

[14]. Guiso N. Bordetella pertussis and Pertussis Vaccines. Clin Infect Dis. 2009;49(10):1565-1569. doi: $10.1086 / 644733$.

[15]. Gabutti G, Azzari C, Bonanni P, et al. Pertussis. Hum Vaccines Immunother. 2014; 11(1):108-117. doi:10.4161/hv.34364.

[16]. Gustafsson L, Hessel L, Storsaeter J, Olin P. Long-term Follow-up of Swedish Children Vaccinated With Acellular Pertussis Vaccines at 3, 5, and 12 Months of Age Indicates the Need for a Booster Dose at 5 to 7 Years of Age. Pediatrics. 2006;118 (3):978-984. doi:10.1542/peds.2005-2746.

[17]. Heininger U, Cherry JD, Christenson PD, et al. Comparative study of Lederle/Takeda acellular and Lederle whole-cell pertussis-component diphtheria-tetanus-pertussis vaccines in infants in Germany. Vaccine. 1994; 12(1):81-86.

[18]. Hawken S, Manuel DG, Deeks SL, Kwong JC, Crowcroft NS, Wilson K. Underestimating the safety benefits of a new vaccine: the impact of acellular pertussis vaccine versus whole-cell pertussis vaccine on health services utilization. Am J Epidemiol. 2012; 176(11):1035-1042. doi:10.1093/aje/kws167.

[19]. Johri AK, Paoletti LC, Glaser P, et al. Group B Streptococcus: global incidence and vaccine development. Nat Rev Microbiol. 2006;4(12):932-942. doi: 10.1038/nrmicro1552.

[20]. Jongerius I, Schuijt TJ, Mooi FR, Pinelli E. Complement evasion by Bordetella pertussis: implications for improving current vaccines. J Mol Med Berl Ger. 2015; 93(4):395-402. doi: 10.1007/s00109-015-1259-1.

[21]. Klein NP, Bartlett J, Fireman B, Rowhani-Rahbar A, Baxter R. Comparative Effectiveness of Acellular Versus Whole-Cell Pertussis Vaccines in Teenagers. Pediatrics. May 2013:peds.2012-3836. doi:10.1542/peds.2012-3836.

[22]. Kline JM, Lewis WD, Smith EA, Tracy LR, Moerschel SK. Pertussis: a reemerging infection. Am Fam Physician. 2013; 88(8):507-514.

[23]. Kiedrzynski T, Bissielo A, Suryaprakash M, Bandaranayake D. Whooping cough—where are we now? A review. N Z Med J. 2015; 128(1416):21-27.

[24]. King AJ, van Gorkom T, van der Heide HG, Advani A, van der Lee S. Changes in the genomic content of circulating Bordetella pertussis strains isolated from the Netherlands, Sweden, Japan and Australia: adaptive evolution or drift? BMC Genomics. 2010; 11:64. doi: 10.1186/1471-2164-11-64.

[25]. Klein NP, Bartlett J, Fireman B, et al. Waning protection following 5 doses of a 3-component diphtheria, tetanus, and acellular pertussis vaccine. Vaccine. 2017; 35 (26):3395-3400. doi:10.1016/j.vaccine.2017.05.008.

[26]. Ligon BL. Pertussis: An historical review of the research and of the development of whole-cell and acellular vaccines. Semin Pediatr Infect Dis. 1998; 9(2):168-178. doi: 10.1016/S1045-1870(98)80068-X.

[27]. Liberia battles whooping cough outbreak. Outbreak News Today. March 2015. http://outbreaknewstoday.com/liberia-battles-whooping-cough-outbreak-33731/. Accessed February 10, 2018.

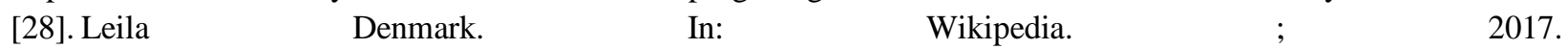
https://en.wikipedia.org/w/index.php?title=Leila_Denmark\&oldid=812452583. Accessed February 10, 2018.

[29]. Lin J, Nishino K, Roberts MC, Tolmasky M, Aminov RI, Zhang L. Mechanisms of antibiotic resistance. Front Microbiol. 2015;6. doi:10.3389/fmicb.2015.00034.

[30]. Lupo A, Coyne S, Berendonk TU. Origin and Evolution of Antibiotic Resistance: The Common Mechanisms of Emergence and Spread in Water Bodies. Front Microbiol. 2012; 3. doi:10.3389/fmicb.2012.00018. 
DOI: $10.21522 / \mathrm{TIJPH} .2013 .06 .02 . A r t 016$

ISSN: $2520-3134$

[31]. Mnookin S. The whole cell pertussis vaccine, media malpractice, and the long-term effects of avoiding difficult conversations. Panic Virus. http://blogs.plos.org/thepanicvirus/2012/09/13/the-whole-cell-pertussis-vaccine-mediamalpractice-and-the-long-term-effects-of-avoiding-difficult-conversations/. Accessed February 10, 2018.

[32]. Miguez Santiyan A, Ferrer Estrems R, Chover Lara JL, Alberola Enguidanos J, Nogueira Coito JM, Salazar Cifre A. Early intervention in pertussis outbreak with high attack rate in cohort of adolescents with complete acellular pertussis vaccination in Valencia, Spain, April to May 2015. Euro Surveill Bull Eur Sur Mal Transm Eur Commun Dis Bull. 2015; 20(27).

[33]. Nowlan M, Turner N, Kiedrzynski T, Murfitt D, Sawicki N. Pertussis control strategies: A consistent approach for New Zealand. Synopsis of Ministry of Health Workshop, April 2015. N Z Med J. 2016; 129(1433):78-85.

[34]. Pertussis | Whooping Cough | Causes and Transmission | CDC. https://www.cdc.gov/pertussis/about/causestransmission.html. Published August 18, 2017. Accessed February 10, 2018.

[35]. Pertussis | Surveillance Trend Reporting and Case Definition | CDC. https://www.cdc.gov/pertussis/survreporting.html. Published February 6, 2018. Accessed February 10, 2018.

[36]. Parton R. Review of the biology of Bordetella pertussis. Biol J Int Assoc Biol Stand. 1999; 27(2):71-76. doi:10.1006/biol.1999.0182.

[37]. Pertuss-surv-report-2013.pdf. https://www.cdc.gov/pertussis/downloads/pertuss-surv-report-2013.pdf.

Accessed February 10, 2018.

[38]. Pertussis | Surveillance Trend Reporting and Case Definition | CDC. https://www.cdc.gov/pertussis/survreporting.html. Published February 6, 2018. Accessed February 10, 2018.

[39]. Porras-Povedano M, Roldán-Garrido A, Santacruz-Hamer V. [Outbreak of Whooping cough in 2016.Écija, Seville, Spain]. Rev Esp Salud Publica. 2017; 91.

[40]. Pertussis Outbreak Among Vaccinated Preschoolers Raises Alarm. Medscape. http://www.medscape.com/viewarticle/857368. Accessed February 10, 2018.

[41]. pertuss-surv-report-2012.pdf. https://www.cdc.gov/pertussis/downloads/pertuss-surv-report-2012.pdf. Accessed February 10, 2018.

[42]. Potin M, Fica A, Véliz L, Moreno G, Wilhelm J, Cerda J. [Strategies to protect the newborn and infants under 6 months of age against pertussis: Statement of the Advisory Committee for Immunizations of the Chilean Infectious Diseases Society]. Rev Chil Infectologia Organo of Soc Chil Infectologia. 2016; 33(5):543-546. doi:10.4067/S0716-10182016000500009.

[43]. Pertussis | Whooping Cough | Surveillance | Cases by Year | CDC. https://www.cdc.gov/pertussis/survreporting/cases-by-year.html. Published February 6, 2018. Accessed February 10, 2018.

[44]. Pichichero ME, Green JL, Francis AB, Marsocci SM, Murphy AM, Buscarino C. Antibody response and reactions to completion of a four-dose series with a two- or three-component acellular pertussis vaccine compared to whole cell pertussis vaccine. Scand J Infect Dis. 1996; 28(2):159-163.

[45]. Rendi-Wagner P, Kundi M, Mikolasek A, Vécsei A, Frühwirth M, Kollaritsch H. Hospital-based active surveillance of childhood pertussis in Austria from 1996 to 2003: estimates of incidence and vaccine effectiveness of whole-cell and acellular vaccine. Vaccine. 2006;24(33-34):5960-5965. doi:10.1016/j.vaccine.2006.05.011.

[46]. Schwartz KL, Kwong JC, Deeks SL, et al. Effectiveness of pertussis vaccination and duration of immunity. CMAJ Can Med Assoc J. 2016; 188(16):E399-E406. doi:10.1503/cmaj.160193.

[47]. Shahcheraghi F, Lotfi MN, Nikbin VS, et al. The First Macrolide-Resistant Bordetella pertussis Strains Isolated From Iranian Patients. Jundishapur J Microbiol. 2014;7(6). doi:10.5812/jjm.10880.

[48]. Simondon F, Yam A, Gagnepain JY, Wassilak S, Danve B, Cadoz M. Comparative safety and immunogenicity of an acellular versus whole-cell pertussis component of diphtheria-tetanus-pertussis vaccines in Senegalese infants. Eur J Clin Microbiol Infect Dis. 1996; 15(12):927-932. doi: 10.1007/BF01690510.

[49]. Sheridan SL, Ware RS, Grimwood K, Lambert SB. Number and order of whole cell pertussis vaccines in infancy and disease protection. JAMA. 2012; 308(5):454-456. doi:10.1001/jama.2012.6364.

[50]. Souder E, Long SS. Pertussis in the Era of New Strains of Bordetella pertussis. Infect Dis Clin North Am. 2015;29(4):699-713. doi:10.1016/j.idc.2015.07.005.

[51]. WHO | Pertussis. WHO. http://www.who.int/biologicals/vaccines/pertussis/en/. Accessed February 10, 2018. 
[52]. Wendelboe AM, Van Rie A, Salmaso S, Englund JA. Duration of immunity against pertussis after natural infection or vaccination. Pediatr Infect Dis J. 2005;24(5 Suppl):S58-61.

[53]. Wagner B, Melzer H, Freymüller G, et al. Genetic Variation of Bordetella pertussis in Austria. PLOS ONE. 2015;10(7):e0132623. doi:10.1371/journal.pone.0132623.

[54]. Xu Y, Wang Y, Tan Y, et al. Production and characterization of recombinant pertactin, fimbriae 2 and fimbriae 3 from Bordetella pertussis. BMC Microbiol. 2009; 9:274. doi: 10.1186/1471-2180-9-274.

[55]. Zhang L, Prietsch SOM, Axelsson I, Halperin SA. Acellular vaccines for preventing whooping cough in children. Cochrane Database Syst Rev. 2014; (9):CD001478. doi:10.1002/14651858.CD001478.pub6.

[56]. Yeung KHT, Duclos P, Nelson EAS, Hutubessy RCW. An update of the global burden of pertussis in children younger than 5 years: a modelling study. Lancet Infect Dis. 2017;17(9):974-980. doi: 10.1016/S14733099(17)30390-0.

[57]. 11_YZhang.pdf. http://www.moleculartb.org/gb/pdf/transcriptions/11_YZhang.pdf. Accessed February 10, 2018.

[58]. 11_YZhang.pdf. http://www.moleculartb.org/gb/pdf/transcriptions/11_YZhang.pdf. Accessed February 11, 2018.

[59]. Zhang L, Prietsch SO, Axelsson I, Halperin SA. Acellular vaccines for preventing whooping cough in children. Cochrane Database Syst Rev. 2011; (1):CD001478. doi:10.1002/14651858.CD001478.pub4. 